\title{
Clinical Features, Diagnosis, and Management of the Antiphospholipid Syndrome
}

\author{
Richard C.W. Wong, F.R.C.P., F.R.A.C.P., F.R.C.P.A., 1 \\ and Emmanuel J. Favaloro, Ph.D., M.A.I.M.S. ${ }^{2}$
}

Almost 30 years after it was first described as a discrete clinical entity, the antiphospholipid syndrome (APS) remains a challenge for clinicians in a wide range of specialities. There remain ongoing issues regarding nomenclature, the expanding range of clinical manifestations, and management of certain APS patient subgroups. In addition to the presence of appropriate clinical features, the diagnosis of APS also fundamentally requires the finding of positive antiphospholipid antibody test result(s), and unfortunately much still has to be done to improve the robustness, reproducibility, and standardization of these assays. This article discusses ongoing dilemmas and issues related to clinical aspects of APS including (i) the derivation of the current nomenclature and the implications of recent proposals for its revision; (ii) the problems that the protean clinical manifestations pose for many clinicians, in particular those not intimately familiar with APS; (iii) the potential pitfalls of applying the APS classification criteria as diagnostic criteria (although no doubt tempting for nonspecialist clinicians); (iv) the concept of seronegative APS and the effect that recent proposed changes in antiphospholipid antibody testing strategies may have on this diagnosis; and finally (v) an overview of key developments in the clinical management of APS patients over the past 30 years.

KEYWORDS: Anti- $\beta 2 \mathrm{GPI}$ antibodies, anticardiolipin antibodies, antiphospholipid antibodies, aPL, antiphospholipid syndrome, APS, clinical features, criteria, diagnosis, management

The antiphospholipid syndrome (APS) is an autoimmune condition characterized by vascular thromboses (arterial and/or venous) and/or pregnancy morbidity in the presence of antiphospholipid (aPL) antibodies. ${ }^{1}$ The importance of this potentially devastating condition is highlighted by the sequential production of two issues of Seminars in Thrombosis and Hemostasis, one dealing primarily with clinical issues ${ }^{2}$ and the other dealing primarily with laboratory issues. ${ }^{3}$ The current article deals with clinical features, diagnosis, and management of aPL antibodies and the APS, as well as historical perspectives and recent data related to pathogenic pathways. We also highlight several of the ongoing dilemmas with clinical aspects of APS, some of which are related to laboratory-associated issues and others that are due to the protean clinical manifestations of this fascinating disease.
${ }^{1}$ Division of Immunology, Pathology Queensland, Royal Brisbane and Womens Hospital, Herston, Queensland, Australia; ${ }^{2}$ Department of Haematology, Institute of Clinical Pathology and Medical Research (ICPMR), Westmead Hospital, NSW, Australia.

Address for correspondence and reprint requests: Dr. Richard C.W. Wong, Division of Immunology, Pathology Queensland (Central Laboratory), Level 4, Block 7, Royal Brisbane and Womens Hospital, Herston, Queensland 4029, Australia (e-mail: richard_wong@health. qld.gov.au).
Antiphospholipid Antibodies and the Antiphospholipid Syndrome I: Pathogenesis, Clinical Features, Diagnosis, and Management; Guest Editors, Emmanuel J. Favaloro, Ph.D., M.A.I.M.S., and Richard C.W. Wong, F.R.C.P., F.R.A.C.P., F.R.C.P.A.

Semin Thromb Hemost 2008;34:295-304. Copyright (C) 2008 by Thieme Medical Publishers, Inc., 333 Seventh Avenue, New York, NY 10001, USA. Tel: +1(212) 584-4662.

DOI 10.1055/s-0028-1082275. ISSN 0094-6176. 
Table 1 Initial Presenting Manifestations of the APS and the Clinical Specialties to which the Patient May Be Referred

\begin{tabular}{ll}
\hline Initial Presenting Manifestations of the APS & Possible Referral to Specialist(s) in the \\
\hline Dermatologic & Following Area(s) \\
Obstetric/pregnancy/infertility related & Dermatologist \\
Most neurologic (e.g., migraine, memory loss) & Obstetrician \\
Some neurologic (e.g., balance disorder, hearing loss) & Neurologist \\
& Neurologist \\
Major thrombosis (arterial and/or venous) & Ear, nose, and throat surgeon \\
& Emergency physician \\
& General physician (internist) \\
& Hematologist \\
Nonthrombotic hematologic (e.g., thrombocytopenia) & Vascular physicians/angiologist \\
Suspected specific organ involvement & Rheumatologist \\
(e.g., kidney, liver, eyes) & Clinical immunologist \\
Skeletal (e.g., ischemic bone fractures) & Hematologist \\
Any of the above (excluding obstetric) in a patient & Organ specialists (e.g., nephrologist, \\
less than 16 years of age & Gastroenterologist/hepatologist, Ophthalmologist) \\
\hline
\end{tabular}

\section{HISTORY AND NOMENCLATURE: WHICH PART OF THE ELEPHANT ARE WE DESCRIBING?}

Before discussing the challenges that clinicians, particularly those not intimately familiar with the field, face when trying to make a diagnosis of APS, we should recognize that APS is a relatively new disease entity. Indeed Graham Hughes, one of the key figures in the discovery of APS, recently quoted the dean of medicine at Barcelona University as saying that APS was one of the two "new" diseases of the late 20th century, the other being AIDS. ${ }^{4}$ It is therefore pertinent that the current issue of Seminars in Thrombosis and Hemostasis covers both the history and nomenclature of this intriguing syndrome, and moreover that this has been largely accomplished by people who have been involved in the investigation of this disease from the time it was first recognized. ${ }^{5,6}$ Indeed, while not wishing to diminish other author contributions to these APS issues of Seminars in Thrombosis and Hemostasis, we remain indebted to the contributions of Nigel Harris, Silvia Pierangeli, and Ronald Asherson and their detailed discussion of the nomenclature of the various subgroups of APS, as this remains one of the many problematic and often controversial aspects of this syndrome. The difficulties with the nomenclature of APS have previously been pointed out by many authors, though Robert Roubey's use of the lyrics of the Beatles song Rocky Raccoon is one of the more novel. ${ }^{7}$ Later in this article, we apply the analogy of blind men describing parts of a large elephant that "they feel but cannot see" to illustrate how APS can perceptually present differently to a diverse range of clinical specialties (Table 1), and thus the importance for these clinicians to recognize the underlying disease process so that the correct diagnosis can be made promptly and appropriate management instituted. From what appears to be a delayed and possibly difficult gestation period, the concept of a primary antiphospholipid syndrome (PAPS) is now firmly established. ${ }^{5,6}$ It now appears that the majority of patients with APS have this subgroup of disease, with no features closely associated with other autoimmune disease, in particular systemic lupus erythematosus (SLE). However, because a small proportion of PAPS patients later appear to evolve features of definite SLE over the next 15 to 20 years, ${ }^{8}$ some experts recommend that all PAPS patients be evaluated clinically and serologically on a regular basis, and for a prolonged period of time, to monitor for such potential development, and this would seem appropriate. ${ }^{6}$ It should be noted that not all studies have reached the same conclusions, but as the median follow-up period is shorter in some of these studies, such an evolution cannot be conclusively excluded. ${ }^{9}$

The latest twist in the life history of this disease, now in early adulthood, is that it currently faces a significant change in nomenclature. The recent 2006 Sydney classification criteria ${ }^{1}$ and consensus opinion from the 2007 International Congress on AntiPhospholipid Antibodies in Florence, Italy, ${ }^{10}$ have recommended that the primary/secondary nomenclature no longer be used. The new proposal is that patients with primary $A P S$ should be described as simply having $A P S$, and the term secondary APS be replaced with $A P S$ and the specific mention of the autoimmune disorder with 
which it is specifically known to be associated.,10 For example, when SLE is present with APS, the patient should be described as having "APS associated with SLE" rather than "secondary APS." However, these proposals have not been universally accepted by all APS researchers. ${ }^{6}$

This proposed change in nomenclature may also pose significant problems in terms of patient classification for ongoing and future APS studies. Patients already entered into prospective studies will need to be "relabeled" from the primary/secondary APS nomenclature to the APS/APS-with-another-autoimmunedisease terminology. Applying the blind men/large elephant analogy, not only are people working in the field describing different parts of the elephant, but during the change-over period in nomenclature, some of them will be speaking slightly different languages. More recent concepts such as the primary plus APS (denoting APS patients who have one or two clinical manifestations that are not included in the current classification criteria for SLE or any other connective tissue disorder $)^{11}$ are also not currently accommodated by the proposed new nomenclature.

\section{PROBLEMS THAT THE PROTEAN CLINICAL MANIFESTATIONS OF APS POSE FOR CLINICIANS}

It is now recognized that a myriad of clinical manifestations can develop in APS. Accordingly, APS is of interest, or at least should be of interest, to a multitude of clinical specialties because of the wide diversity of these clinical manifestations, which may affect virtually any organ in the body, including the lung, skin, brain, liver, kidneys, adrenal glands, heart, and eyes. ${ }^{4,12}$ The recognized "classic" clinical presentations include peripheral deep venous thrombosis (DVT), pulmonary embolism (PE), and/or arterial thrombotic events, frequently but not always accompanied by thrombocytopenia and livedo reticularis. However, a vast range of other clinical manifestations has been observed including some presentations that may not be intuitively linked with APS, such as ischemic bone fractures, renal and celiac artery stenosis, and a possible tendency toward accelerated atherosclerosis. ${ }^{4}$ Dermatologic manifestations other than livedo reticularis also occur in a large percentage of APS patients and may be the first presenting physical feature of this condition. ${ }^{13}$ Interestingly, although thrombosis is a key mechanism in many of these manifestations, some clinical manifestations do not involve purely thrombotic or ischemic mechanisms, for example chorea. $^{14}$

Obstetric manifestations including recurrent miscarriages, early-onset and severe preeclampsia, and possibly primary infertility are the initial presenting feature in a significant proportion of APS patients and may remain their only manifestation(s) of APS. ${ }^{15}$ Indeed, before the concept of APS was introduced, there were published reports of obstetric manifestations in patients that would now be considered as having definite APS. ${ }^{16,17}$ Once again, although it is intuitive to invoke thrombotic mechanisms for these obstetric manifestations, it is becoming clear that nonthrombotic mechanisms also play an important role, particularly with respect to the defective placentation that occurs in many women with APS. ${ }^{18}$ This knowledge has also shed new light on how some established therapies may work in APS-related obstetric disease. For example, in addition to being an anticoagulant, heparin may partially exert its pregnancy-prolonging effects (in APS) by binding to the phospholipid binding sites on $\beta 2 \mathrm{GPI}$, resulting in $\beta 2$ GPI being displaced from the trophoblast surface and thus no longer being available to bind to anti- $\beta 2 \mathrm{GPI}^{18}$

It is this wide diversity in clinical presentations that may cause problems in the diagnosis and treatment of APS. Take, for example, a patient with APS that initially presents to a general practitioner with some of the "nonclassic" manifestations of APS (i.e., features other than significant venous and/or arterial thrombosis). The general practitioner may or may not recognize these manifestations to be part of APS, may or may not attempt some form of therapy related to the presenting clinical manifestations, or may alternatively refer the patient to a specialist. In this latter situation, the specialist chosen will be dependent on both the presenting clinical features and the general practitioner's preferences. For example, if there are dermatologic manifestations, the general practitioner may refer the patient to a dermatologist. If the dermatologist is aware of the need to consider APS within the context of the clinical features, then the patient may be diagnosed and treated appropriately at an early stage of their disease and be spared future serious consequences. However, if the dermatologist does not recognize the dermatologic manifestations as a feature of APS, then treatment might simply entail observation or topical therapies that would not deal with the underlying disease. A similar situation may also occur with initial presentations to other specialists. Thus, an initial presentation of recurrent miscarriage may result in referral to an obstetrician, whereas initial presentation of migraines may lead to referral to a neurologist, and so on (Table 1). Subsequent diagnosis and management might then be differentially applied.

Alternatively, the patient may present to the emergency department of a hospital with one of the more severe classic manifestations of APS (such as PE, lower-limb DVT, or stroke). Again, the diagnosis of APS may or may not be considered by the attending medical staff. For example, if there is another predisposing factor for DVT (e.g., recent long-haul plane travel), APS may not be considered and the patient 
might simply be treated with short-term anticoagulation, without further specialist referral. Most importantly, a failure or significant delay in recognizing APS as the underlying disease entity may lead to the loss of an opportunity to prevent potentially serious consequences of the disease, in particular major subsequent venous and/or arterial thrombotic events.

Returning to the example of our original general practitioner, even if he or she was savvy enough to suspect APS, he or she then has the dilemma of which aPL tests to order so as to make or exclude the diagnosis. There is now a very wide range of such tests feasibly available that could be used to diagnose this syndrome (including anticardiolipin [aCL] antibodies, anti$\beta 2 \mathrm{GPI}$, lupus anticoagulant [LA], antiprothrombin, antiphosphatidylserine, and the various isotypes of these antibodies). Indeed, there is still ongoing intense discussion regarding which of these tests should constitute a preliminary "routine" screen. ${ }^{19}$ For example, some authors suggest only $\operatorname{IgG} \mathrm{aCL}$ and $\mathrm{LA}$, whereas others would suggest IgG/IgM aCL, IgG/IgM anti- $\beta 2 \mathrm{GPI}$, and LA.

Having decided which aPL tests to perform, most clinicians not intimately familiar with APS (and perhaps even some who are) would presume that these aPL tests are robust, reproducible, and well standardized, like the routine hematology and biochemistry tests they otherwise request. However, it is clear to those working in the field that this is unfortunately not the case for many aPL tests and arguably may never be possible. ${ }^{20-22}$ These important issues regarding which aPL tests should be requested and the limitations of currently available aPL assays are briefly discussed in a few other articles in this issue of Seminars in Thrombosis and Hemostasis and will also be covered in greater detail within the next issue dealing with laboratory matters (Seminars in Thrombosis and Hemostasis, volume 34, number 4$)^{23}$

The test report issued by the laboratory and its content is also an important postanalytical variable affecting the diagnosis of APS. A survey on aCL reporting practices in Australia and New Zealand in 2001 found that 9 of 32 respondent laboratories did not provide any interpretative comments in their reports. ${ }^{24}$ Of the 23 laboratories that did provide comments, 10 did not provide any comment with negative aCL results, 8 did not comment that positive aCL results might be found in non-autoimmune conditions such as infections, and only 5 commented that the risk of thrombosis increased with the level of aCL. Clinicians not intimately familiar with aPL testing (including the vast majority of general practitioners) are likely to place considerable reliance on these interpretative comments, and this variation in laboratory practice related to interpretative comments could significantly affect whether an APS patient with a nonclassic clinical presentation is appropriately diagnosed or not. In particular, these clinicians may only order the $\mathrm{aCL}$ test as a screening test for APS and make or exclude a diagnosis of APS based on this test result alone. Therefore, if the laboratory report does not indicate statements that a negative aCL result does not necessarily exclude the diagnosis of APS and/or indicate that other testing (in particular LA) should be performed, the diagnosis of APS may be missed. Accordingly, the Australasian Anticardiolipin Antibody Working Party considered it a priority to include sample interpretative comments in its published consensus guidelines on aCL antibodies ${ }^{25}$ and anti$\beta 2 \mathrm{GPI}^{26}$ antibody testing and reporting.

After receiving the test report containing the aPL test results and interpretative comments (if provided), depending on the patient's symptoms/signs and the general practitioner's clinical judgment/referral base, the patient may be differentially referred to a range of specialists. Depending on the location and availability of specialist units with an interest in APS, the patient may end up seeing a hematologist, rheumatologist, clinical immunologist, or even a vascular physician/angiologist. Subsequent diagnosis and management might then again be differentially applied. There are even cases of so-called seronegative antiphospholipid syndrome (SNAPS) to consider (discussed in greater detail in the "Seronegative APS" section). ${ }^{11,27}$

These problems illustrate why APS remains one of the more challenging diagnostic entities in clinical medicine. The current issue of Seminars in Thrombosis and Hemostasis therefore contains articles from clinical experts in several clinical specialties who discuss the relevant clinical manifestations of APS in their specialties, as well as relevant management. ${ }^{12,14,15,28-30}$ The linked concept of clinical presentation as a preanalytical variable to the laboratory identification of aPL antibodies is also taken further in a subsequent article in the next issue of Seminars in Thrombosis and Hemostasis. ${ }^{23}$

Finally, given that APS clearly poses significant diagnostic challenges to clinicians not intimately familiar with the field, more work needs to be done to disseminate some of the knowledge base to those clinicians, including the vast majority of general practitioners, who are less likely to read specialist reviews on APS.

\section{POTENTIAL PITFALLS OF APPLYING THE APS CLASSIFICATION CRITERIA AS DIAGNOSTIC CRITERIA}

Virtually all of the articles in this clinical issue of Seminars in Thrombosis and Hemostasis refer to the original 1999 Sapporo $^{31}$ and revised 2006 Sydney $^{1}$ classification criteria for APS. As Harris and Pierlangeli remind us in the first article of this issue, ${ }^{5}$ and as their 
name implies, these are primarily classification (as opposed to diagnostic) criteria, developed and refined to maximize the possibility that patients who satisfy these criteria actually have the disease and can be appropriately included into prospective studies on APS. Accordingly, some patients with clinical APS will not satisfy these classification criteria, and this is strongly reiterated by Harris and Pierlangeli in their article on the nomenclature of APS. ${ }^{5}$ Indeed, the clinical validation of the 1999 Sapporo criteria by Lockshin et al in $2000^{32}$ showed that to achieve a specificity for APS of $98 \%$, the sensitivity of the criteria was only $71 \%$; in other words, $29 \%$ of APS patients in this study did not satisfy the 1999 Sapporo criteria. After intense discussion at the 2005 XIth International Congress on Antiphospholipid Antibodies in Sydney, Australia, the clinical criteria were left unchanged in the 2006 revised criteria, but the laboratory criteria were expanded to include positive $\mathrm{IgG}$ and/or IgM anti- $\beta 2 \mathrm{GPI}$ antibody findings, and the requirement for aCL testing to be performed in a $\beta 2 \mathrm{GPI}-$ dependent manner was removed. ${ }^{1}$ These issues are covered in greater depth in the subsequent laboratory issue of this journal, ${ }^{3}$ but it is evident that these changes may result in a reduction in specificity of the criteria for APS, in particular due to the inclusion of patients with positive non-cofactor-related aCL results as their laboratory criteria. ${ }^{33,34}$ Therefore, it would be very useful to have another clinical validation study performed to determine whether these revisions to the laboratory criteria have significantly affected their specificity and/ or sensitivity for APS.

It is also very important to recognize that the consensus process used to create and revise the classification criteria is not foolproof. Such a process usually results in broad (e.g., 70 to $90 \%$ ) rather than complete (100\%) agreement on most of the more contentious issues, as discussed in greater depth elsewhere. ${ }^{23}$ There is also a significant component of eminence-based rather than evidence-based input into the process, partially due to the relative paucity of good-quality prospective clinical studies in this area. In this regard, the real value of the APS classification criteria is that they have allowed the establishment of large APS patient registries in both North America and Europe, which hopefully might provide answers to some of the more contentious issues in the management of APS.

The significance of the above concerns can be better recognized when some clinicians mistakenly "strictly" apply the classification criteria to make or exclude a clinical diagnosis in a patient suspected of APS. In this situation, a proportion of patients with clinical APS (almost $30 \%$ in the study of Lockshin et $\mathrm{al}^{32}$ as an example) may have the diagnosis of APS incorrectly excluded and thus may not be given appropriate therapy leading to potentially significant adverse consequences. Instead, the important take-home message is that even if such a patient does not fully satisfy the classification criteria, he or she may still have APS and thus require appropriate management, including anticoagulation. ${ }^{5}$

\section{SERONEGATIVE APS: THE POTENTIAL EFFECT OF THE REVISED CLASSIFICATION CRITERIA AND PROPOSED CHANGES IN APL TESTING STRATEGIES}

The term seronegative antiphospholipid syndrome (SNAPS) was first coined by McCarty and colleagues in an abstract in $2000^{27}$ when describing 53 patients with typical clinical manifestations of the APS but who were negative for a range of aPL antibodies. It is recommended that to make a diagnosis of SNAPS, the patient should be seronegative for all types (i.e., aCL, anti- $\beta 2 \mathrm{GPI}$, etc.) and all antibody isotypes (i.e., IgG, IgM, and IgA) of aPL antibodies including LA at the time of the thrombotic event. ${ }^{6}$ A careful differential diagnosis from other prothrombotic conditions is also required. Additionally, some patients with Sneddon's syndrome are persistently negative for aPL antibodies and have clinical features that are similar to those who are aPL antibody positive. In one of his articles in this issue of the journal, Asherson argues that perhaps these cases represent a completely different type of vasculopathy, predominately affecting the skin and cerebrovascular arterioles rather than being a variant of APS. ${ }^{6}$

Asherson has also outlined several possible explanations for transient aPL seronegativity in APS patients: (i) 20 to $30 \%$ of APS patients are positive only for aCL or LA, thus recommending that both tests should always be performed in all cases of suspected APS; (ii) aCL and LA may transiently fall to undetectable levels due to "consumption" at the time of the thrombotic event, and thus if initially negative, both tests should be repeated after resolution of the event ${ }^{35}$; and also (iii) some APS patients may only have antibodies to phospholipids other than cardiolipin (e.g., phosphatidylserine or phosphatidylethanolamine) ${ }^{6}$

However, this last explanation raises a significant dilemma regarding how many aPL tests should a diagnostic laboratory routinely offer for clinicians? Most Australian diagnostic laboratories offer IgG and $\mathrm{IgM}$ isotypes of $\mathrm{aCL},{ }^{24}$ along with $\mathrm{LA}$ testing, with anti- $\beta 2 \mathrm{GPI}$ testing (IgG isotype primarily) being available in a more limited number of diagnostic laboratories. However, none currently offer antiprothrombin, antiphosphatidylserine, or antiphosphatidylethanolamine testing. Thus, for a patient with a clinical picture consistent with APS but negative $\mathrm{aCL}$, anti- $\beta 2 \mathrm{GPI}$, and LA test results, the attending clinician and the relevant diagnostic laboratory have to make a decision regarding whether to spend the time and expense (potentially quite significant) to get these 
additional aPL tests performed overseas or simply to make a diagnosis of SNAPS.

The requirement for aCL assays to be performed in a $\beta 2$ GPI-dependent manner has been removed in the Sydney APS classification criteria, ${ }^{1}$ and this would be expected to increase the number of $\beta 2 \mathrm{GPI}$-independent (false-positive) aCL results. Partially prompted by this change, several experts in the APS field have recommended that the aCL test should be completely abandoned and replaced by the anti- $\beta 2 \mathrm{GPI}$ test, to reduce the number of false-positive (largely $\beta 2 \mathrm{GPI}$-independent) aCL test results. ${ }^{22,33}$ However, this recommendation could have significant implications regarding the number of APS patients considered to have SNAPS. In particular, as discussed below, the complete abandonment of the aCL test, one of the major (albeit flawed) tests for aPL antibodies, may increase the number of patients being diagnosed with SNAPS or, more worrying, not even being recognized as having APS.

By pooling their data with that from four earlier studies comparing anti- $\beta 2 \mathrm{GPI}$ and $\mathrm{aCL}$ assays, Helbert et $\mathrm{al}^{36}$ have shown that while the anti- $\beta 2 \mathrm{GPI}$ assay was more specific than the $\mathrm{aCL}$ assay (anti- $\beta 2 \mathrm{GPI}$ pooled specificity was close to $99 \%$ compared with close to $90 \%$ for $\mathrm{aCL}$ ), this was at the expense of significantly lower sensitivity for APS. Indeed, the pooled anti- $\beta 2 \mathrm{GPI}$ sensitivity for APS was $\sim 75 \%$ compared with more than $95 \%$ for aCL. ${ }^{36}$ This means that using the assays in these studies, some APS patients will be negative for anti- $\beta 2 \mathrm{GPI}$ even though they are $\mathrm{aCL}$ positive. Although the anti- $\beta 2$ GPI assays used in these five studies (four of five performed prior to 2000) may have been relatively insensitive (for reasons discussed in greater depth in the next issue of the journal) ${ }^{23} \mathrm{com}^{-}$ pared with currently available anti- $\beta 2$ GPI assays, the implications of using a less sensitive diagnostic test in patients with a moderate to high pretest probability for APS are significant. If the aCL test was no longer routinely available to evaluate patients with suspected APS who are anti- $\beta 2$ GPI and LA negative, these patients would have to be considered as having SNAPS. Alternatively and of more concern, a clinician who is unfamiliar with the differing diagnostic properties of the anti- $\beta 2 \mathrm{GPI}$ and $\mathrm{aCL}$ tests may mistakenly exclude the diagnosis of APS entirely and may withhold appropriate therapy (including anticoagulation) with potentially significant adverse outcomes for the patient.

This discussion illustrates the tight interplay between laboratory tests for aPL antibodies and the clinical diagnosis of APS, given that the fundamental concept of APS requires that these patients must have appropriate clinical manifestations and positive aPL test result(s). The APS community thus has to be aware of the potentially profound implications that significant changes in laboratory testing panels and practices may have for the vast majority of clinicians, especially those who are less familiar or not familiar with the laboratory aspects of aPL testing.

\section{MANAGEMENT OF APS: WHAT HAVE WE LEARNED FROM THE PAST 30 YEARS?}

Given that this disease entity has only been formally recognized for just under 30 years, it is not surprising that there is still much to be learned about APS. However, management has arguably not progressed very far over the past 20 years since the recognition of the syndrome. The treatment of most patients with thrombotic complications is very similar to that of patients with non-APS-related thrombosis, with heparin therapy followed by oral anticoagulation. Asherson and colleagues provide a concise review of the current treatment of APS. ${ }^{12}$ From this, it is apparent that recent advancements in treatment of nonobstetric APS have been limited to three areas. First, there has been expanding knowledge regarding the use of subcutaneous low-molecular-weight heparin (LMWH) versus unfractionated intravenous heparin. Second, two large, prospective, randomized trails were published in the past 5 years that have suggested moderate-intensity (target international normalized ratio [INR] range 2.0 to 3.0 ) rather than high-intensity (INR range $>3.0)^{37}$ oral anticoagulation with warfarin is equally effective in preventing rethrombosis with less bleeding complications after an aPL-related venous thrombosis. ${ }^{38,39}$ However, the applicability of these results to patients with aPL-related arterial thrombosis is less certain, as such patients constituted less than half the patients in the study populations, and thus eminence-based, rather than evidence-based, treatment strategies largely remain for this patient group. ${ }^{12}$ Third, the recent randomized, double-blind, placebo-controlled APLASA study by Erkan and colleagues ${ }^{40}$ found that low-dose aspirin (LDA; $81 \mathrm{mg} /$ day) was not superior to placebo in preventing first thrombotic episodes in asymptomatic persistently aPL-positive individuals, although the incidence rate of first thrombosis in the study population was relatively low. However, the concomitant presence of SLE is considered to be an independent risk factor for the development of thrombosis in persistently positive aPL subjects, and thus these patients should be managed more aggressively. The authors therefore recommend that ideally primary thrombosis prevention strategy in asymptomatic persistently aPL-positive individuals needs to be risk-stratified and determined according to the individual's age, traditional cardiovascular risk factors, presence or absence of other systemic autoimmune diseases, as well as which aPL tests were positive. ${ }^{40}$

In obstetric APS, the current standard of care to prevent fetal loss in pregnant women with APS (with no prior venous or arterial thrombotic event) is the 
Table 2 Important Ongoing Issues in the Diagnosis and Management of APS (See Text for Further Details)

\begin{tabular}{lc}
\hline Diagnostic / Management Issue & Current Situation \\
\hline Revision of primary/secondary & The 2006 Sydney classification criteria and \\
nomenclature & 2007 Phospholipid Conference in \\
& Florence (Italy) recommend that the \\
& primary/secondary nomenclature be \\
& replaced with APS and specific \\
& mention of any autoimmune disorder \\
& known to be associated with APS. \\
Clinicians may use the APS classification \\
criteria when trying to make a diagnosis \\
of APS in patients suspected of having \\
the disease, as opposed to their \\
intended purpose to appropriately \\
classify APS patients for inclusion \\
into prospective trials. \\
How mans
\end{tabular}

Comments

Patients currently enrolled in prospective trials will need to be relabeled. Concept of primary plus APS is not accommodated by proposed new nomenclature.

Patients who only partially satisfy the APS classification criteria may be misdiagnosed as not having APS and thus denied appropriate therapy, with potentially significant adverse outcomes for the patient.

Many routine diagnostic laboratories offer $\mathrm{aCL}$, anti- $\beta 2 \mathrm{GPI}$, and lupus anticoagulant testing. Expanding the number of isotypes of these antibodies and other aPL tests will increase the complexity and cost of routine testing, and may also increase the identification of false positive cases.

Some authors are proposing that the $\mathrm{aCL}$ test be removed and replaced with the anti- $\beta 2 \mathrm{GPI}$ test to improve overall specificity.

\section{Optimal management of APS patients with arterial thrombosis, and/or recurrent thrombosis despite standard anticoagulant therapy}

Persistently aPL-positive patients on warfarin
Two large, prospective, randomized studies have suggested moderate intensity (INR range 2.0 to 3.0 )

is equally effective to high intensity (INR range > 3.0) for aPL-related venous thrombosis. However, the optimal INR range for patients with aPL-related arterial thrombosis is still uncertain as they constituted less than half the study population.

Persistently aPL-positive patients currently taking warfarin who developed their thrombotic event triggered by an acquired and reversible thrombotic risk factor and do not have an identifiable genetic hypercoagulable state.
Because of its higher specificity, the anti- $\beta 2 \mathrm{GPI}$ test is less sensitive than the aCL test, and therefore some APS patients may be anti- $\beta 2 \mathrm{GPI}$ negative but $\mathrm{aCL}$ positive. If the aCL test is no longer routinely available, these patients may be diagnosed as having SNAPS, or more worrying, not be recognized as having APS at all.

Further prospective randomized studies are required specifically addressing patients with aPL-related arterial thrombosis. In addition, the management of patients with recurrent thrombosis (venous and/or arterial) despite standard anticoagulant therapy is currently limited to case reports and small case series.

There is still insufficient risk-stratified data to determine if such patients may be able to safely discontinue warfarin or switch to aspirin. 
Table 2 (Continued)

\begin{tabular}{|c|c|c|}
\hline Diagnostic / Management Issue & Current Situation & Comments \\
\hline $\begin{array}{l}\text { Novel therapies for APS based } \\
\text { on better understanding of } \\
\text { the pathogenic processes }\end{array}$ & $\begin{array}{l}\text { Aberrant pathophysiologic conditions } \\
\text { (including oxidative stress) may render } \\
\text { natural aPL antibodies pathogenic or } \\
\text { pathologic. Thrombosis in APS may } \\
\text { require a double-hit mechanism. }\end{array}$ & $\begin{array}{l}\text { Identification of specific aberrant } \\
\text { pathophysiologic circumstances may } \\
\text { allow better prediction of when APS } \\
\text { patients require more intensive } \\
\text { monitoring and/or aggressive therapy, } \\
\text { as well as instituting measures to } \\
\text { correct the aberrant pathophysiologic } \\
\text { circumstances. } \\
\text { Novel therapies that interfere with first-hit } \\
\text { mechanisms may reduce the risk of } \\
\text { thrombosis developing when second-hit } \\
\text { events occur. }\end{array}$ \\
\hline $\begin{array}{l}\text { Establishment of large APS } \\
\text { patient registries }\end{array}$ & $\begin{array}{l}\text { The } 1999 \text { Sapporo and } 2006 \text { Sydney } \\
\text { classification criteria for APS have } \\
\text { enabled establishment of } \\
\text { large APS patient registries in both } \\
\text { North America and Europe. }\end{array}$ & $\begin{array}{l}\text { These patient registries will make it easier } \\
\text { to conduct prospective studies that allow } \\
\text { more valid investigation of a range of } \\
\text { therapies and management strategies, } \\
\text { rather than retrospective case-control } \\
\text { studies and case reports. An example } \\
\text { of such a prospective randomized trail } \\
\text { with useful conclusions is the } \\
\text { APLASA study. }{ }^{40}\end{array}$ \\
\hline $\begin{array}{l}\text { Internet-based registries for } \\
\text { rarer subgroups of APS }\end{array}$ & $\begin{array}{l}\text { Internet-accessible CAPS Registry, } \\
\text { maintained by Ricard Cervera's } \\
\text { group at the University of Barcelona } \\
\text { Web site: http://www.med.ub.es/ } \\
\text { MIMMUN/FORUM/CAPS.HTM. }\end{array}$ & $\begin{array}{l}\text { Has enabled the pooling of the clinical } \\
\text { experience of an otherwise rare condition } \\
\text { that any individual clinician or unit might } \\
\text { only see once or twice per year. } \\
\text { This has led to the publication of various } \\
\text { insights into the frequency of differing } \\
\text { clinical manifestations well as the various } \\
\text { treatment modalities used in CAPS patients. }\end{array}$ \\
\hline
\end{tabular}

combination of LDA and LMWH, though one randomized controlled study found that this combination was not superior to LDA alone. ${ }^{15,41}$ Importantly, a small, randomized prospective study showed that the addition of corticosteroids (CS) to LDA did not confer a significant advantage with respect to successful pregnancy outcome. ${ }^{42}$ However, the use of CS was associated with more obstetric side effects, in particular diabetes, preeclampsia, and premature birth, which was confirmed in two other randomized controlled studies. ${ }^{43,44}$ Hence, CS are currently not recommended as standard therapy to prevent fetal loss in pregnant women with APS ${ }^{15,45}$ but may be indicated for other concomitant autoimmune conditions (e.g., SLE). The evidence for using intravenous immunoglobulins (IVIG) to prevent fetal loss and prolong pregnancy remains limited to case reports. ${ }^{45}$

Knowledge related to treatment of the most severe form of APS, the catastrophic APS (CAPS), has been greatly assisted by the Internet-accessible CAPS Registry, maintained by Ricard Cervera's group at the University of Barcelona, who provide a article on this topic in this issue of Seminars in Thrombosis and
Hemostasis. ${ }^{30}$ Based partly on the findings of this registry, the combined use of anticoagulation (AC), corticosteroids (CS), and plasma-exchange (PE) is currently recommended as first-line therapy. However, many clinicians substitute IVIG for plasma-exchange due to lack of facilities for performing plasma exchange. With such therapy, the mortality rate in patients with CAPS appears to be improving but is still high at $33.3 \%$ in CAPS Registry patients diagnosed between 2001 and February 2005.

Therefore, there is still insufficient risk-stratified data to determine whether warfarin-receiving, persistently aPL-positive patients, who had developed an event triggered by an acquired and reversible thrombotic risk factor (e.g., prolonged immobility, oral contraceptive pill, trauma) and do not have an identifiable genetic hypercoagulable state, may be able to safely discontinue warfarin or switch to aspirin. The role of non-anticoagulant drugs such as hydroxychloroquine and the HMG-CoA reductase inhibitors (statins) has been supported by experimental evidence but not been further evaluated by formal randomized clinical trials. The use of 
rituximab, an anti-CD20 monoclonal antibody, has also been recently described in case reports, particularly in the context of CAPS. ${ }^{46-48}$

Thus, as with any other disease entity, detailed knowledge of the pathogenesis of the condition is required to develop more targeted treatments, both prophylactic and therapeutic. It is therefore valuable to have three articles in this issue of Seminars in Thrombosis and Hemostasis that review current knowledge regarding the pathogenesis of APS. ${ }^{12,18,49}$ The double-hit hypothesis is covered in detail by Periangeli and colleagues. ${ }^{18}$ With this knowledge comes the hope that novel treatments may be developed that not only interfere with the firsthit mechanisms and reduce the risk of thrombosis developing when second-hit events occur but also achieve this with less toxicity than that of current treatments (mainly anticoagulation). This would certainly be appealing as second-hit events (such as infection, trauma, and surgery) are not always possible to prevent. Asherson et $\mathrm{al}^{12}$ provide a summary of the basic immunologic concepts related to the origin of autoantibodies in general but also specifically relevant to aPL antibodies. An important part of this section is the concept of "natural autoantibodies" and aberrant pathophysiologic circumstances (including oxidant stress) whereby dysregulation of the normal control mechanisms of these autoantibodies may occur, thereby rendering them pathogenic or pathologic. This may explain why the widespread thrombotic characteristic of CAPS often occurs in the context of aberrant pathophysiologic circumstances where oxidative stress is present (e.g., severe infection and surgery, including organ transplantation). Accordingly, recognition of these specific pathophysiologic circumstances may allow better prediction of when APS patients require more intensive monitoring and aggressive therapy, as well as instituting measures to correct the aberrant pathophysiologic circumstances.

\section{CONCLUSION}

The antiphospholipid syndrome remains a challenge for clinicians in a wide range of specialties, both in terms of making the diagnosis and the subsequent management of the patients identified. The range of possible pathogenic mechanisms, protean clinical manifestations, possible changes in nomenclature, reliance on "unreliable" aPL assays to make the diagnosis (with the exception of SNAPS), and the relative lack of prospective clinical trials makes APS a fertile ground for ongoing basic, clinical, and diagnostic laboratorybased research and vigorous discussion well into the 21st century (Table 2). Different clinical presentations and different specialist perceptions also means that many of us only see certain parts of this very large elephant (Table 1).

\section{REFERENCES}

1. Miyakis S, Lockshin MD, Atsumi T, et al. International consensus statement on an update of the classification criteria for definite antiphospholipid syndrome (APS). J Thromb Haemost 2006;4:295-306

2. Wong RC, Favaloro EJ. Antiphospholipid antibodies and the antiphospholipid syndrome I: pathogenesis, clinical features, diagnosis, and management. Semin Thromb Hemost 2008; 34:213-218

3. Favaloro EJ, Wong RC. Antiphospholipid antibodies and the antiphospholipid syndrome II: limitations, standardisation, and clinical utility of laboratory testing. Semin Thromb Hemost 2008;34: (in press)

4. Hughes G. Hughes syndrome. The antiphospholipid syndrome-a clinical overview. Clin Rev Allergy Immunol 2007; 32:3-11

5. Harris EN, Pierangeli SS. Primary, secondary, and catastrophic antiphospholipid syndrome: what's in a name? Semin Thromb Hemost 2008;34:219-226

6. Asherson RA. The primary, secondary, catastrophic, and seronegative variants of the antiphospholipid syndrome: a personal history long in the making. Semin Thromb Hemost 2008;34:227-235

7. Roubey R. Immunology of the antiphospholipid antibody syndrome. Arthritis Rheum 1996;39:1444-1454

8. Seisdedos L, Muñoz-Rodriguez FJ, Cervera R, Font J, Ingelmo M. Primary antiphospholipid syndrome evolving into systemic lupus erythematosus. Lupus 1997;6:285-286

9. Gómez-Puerta JA, Martin H, Amigo M-C, et al. Long term follow-up in 128 patients with primary antiphospholid syndrome. Do they develop lupus? Medicine 2005;84:225230

10. Meroni PL, Tincani A. 12th International Congress on Anti-Phospholipid Antibodies. 2007. Available at: http:// www.antiphospholipid.net/committees.htmlAccessed April 7, 2008

11. Asherson RA, Schamroth-Rapaport N, Skudowitz B, et al. Recurrent deep vein thrombosis, ovarian carcinoma and antibodies to mitochondria M5 in a patient with asymptomatic primary "plus" antiphospholipid syndrome: an unusual combination. Clin Exp Rheumatol 2007;25:890-895

12. Asherson RA, Cervera R, Merrill JT, Erkan D. Antiphospholipid antibodies and the antiphospholipid syndrome: clinical significance and treatment. Semin Thromb Hemost 2008;34:256-266

13. Blume JE, Miller CC. Antiphospholipid syndrome: a review and update for the dermatologist. Cutis 2006;78:409-415

14. Miesbach W. Neurological symptoms as a feature of the antiphospholipid syndrome. Semin Thromb Hemost 2008; 34:286-289

15. Tincani A, Bazzani C, Zingarelli S, Lojacono A. Lupus and the antiphospholipid syndrome in pregnancy and obstetrics: clinical characteristics, diagnosis, pathogenesis, and treatment. Semin Thromb Hemost 2008;34:

16. Sourlier JP, Boffa MC. Avortements à répétition, thromboses, et anticoagulant circulant anti-thromoboplastine. Nouv Presse Med (Paris) 1980;9:859-864

17. Nilsson IM, Asstedt B, Hedner D, Berezin B. Intrauterine death and circulating anticoagulant ("antithromboplastin"). Acta Med Scand 1975;197:153-159

18. Pierangeli SS, Chen PP, Elena R, et al. Antiphospholipid antibodies and the antiphospholipid syndrome: pathogenic mechanisms. Semin Thromb Hemost 2008;34:236-250 
19. Galli M, Reber G, de Moerloose P, de Groot PG. Invitation to a debate on the serological criteria that define the antiphospholipid syndrome. J Thromb Haemost 2008;6:399-401

20. Pierangeli SS, Harris EN. A quarter of a century in anticardiolipin antibody testing and attempted standardization has led us to here, which is? Semin Thromb Hemost 2008;34 (in press)

21. Andreoli L, Rizzini S, Allegri S, Meroni P, Tincani A. Are the current attempts at standardization of antiphospholipid antibodies still useful? Emerging technologies signal a shift in direction. Semin Thromb Hemost 2008;34 (in press)

22. Reber G, Boehlen F, de Moerloose P. Technical aspects in laboratory testing for antiphospholipid antibodies: Is standardization an impossible dream? Semin Thromb Hemost 2008;34 (in press)

23. Favaloro EJ, Wong RC. Laboratory testing and identification of antiphospholipid antibodies and the antiphospholipid syndrome: limitations, standardization, and clinical utility. Semin Thromb Hemost 2008;34 (in press)

24. Wong RC, Wilson RJ, Pollock W, Steele RH, Gillis D. Anti-cardiolipin antibody testing and reporting practices among laboratories participating in a large external Quality Assurance Program. Pathology 2004;36:174-181

25. Wong RCW, Gillis D, Adelstein S, et al. Consensus guidelines on anti-cardiolipin antibody testing and reporting. Pathology 2004;36:63-68

26. Wong RC, Favaloro EJ, Adelstein S, et al. Consensus guidelines on anti-beta 2 glycoprotein I testing and reporting. Pathology 2008;40:58-63

27. McCarthy GA, et al. Seronegative APS (SNAPS) in 53 patients: seroconversion rate at 3.5 yrs [abstract]. J Autoimmun 2000;15:OC35

28. Hunt BJ. Paediatric antiphospholipid antibodies and antiphospholipid syndrome. Semin Thromb Hemost 2008; 34:274-281

29. Miesbach W. Antiphospholipid antibodies and antiphospholipid syndrome in patients with malignancies: features, incidence, identification, and treatment. Semin Thromb Hemost 2008;34:282-285

30. Espinosa G, Bucciarelli S, Asherson RA, Cervera R. Morbidity and mortality in the catastrophic antiphospholipid syndrome: pathophysiology, causes of death, and prognostic factors. Semin Thromb Hemost 2008;34:290-294

31. Wilson WA, Gharavi AE, Koike $\mathrm{T}$, et al. International consensus statement on preliminary classification criteria for definite antiphospholipid syndrome: report of an international workshop. Arthritis Rheum 1999;42:1309-1311

32. Lockshin MD, Sammaritano LR, Schwartzman S. Validation of the Sapporo criteria for antiphospholipid syndrome. Arthritis Rheum 2000;43:440-443

33. Galli M. Clinical utility of laboratory tests used to identify antiphospholipid antibodies and to diagnose the antiphospholipid syndrome. Semin Thromb Hemost 2008;34 (in press)

34. de Groot PG, Derksen RH, de Laat B. Twenty-two years of failure to set-up undisputed assays to detect patients with the antiphospholipid antibodies. Semin Thromb Hemost 2008; 34 (in press)
35. Miret C, Cervera R, Reverter JC, et al. Antiphospholipid syndrome without antiphospholipid antibodies at the time of the thrombotic event: transient 'seronegative' antiphospholipid syndrome? Clin Exp Rheumatol 1997;15:541-544

36. Helbert M, Bodger S, Cavenagh J, et al. Optimising testing for phospholipid antibodies. J Clin Pathol 2001;54:693698

37. Khamashta MA, Cuadrado MJ, Mujic F, et al. The management of thrombosis in the antiphospholipid-antibody syndrome. N Engl J Med 1995;332:993-997

38. Crowther MA, Ginsberg JS, Julian J, et al. Comparison of two intensities of warfarin for the prevention of recurrent thrombosis in patients with the antiphospholipid antibody syndrome. N Engl J Med 2003;349:1133-1138

39. Finazzi G, Marchioli R, Brancaccio V, et al. A randomized clinical trial of high-intensity warfarin vs. conventional antithrombotic therapy for the prevention of recurrent thrombosis in patients with the antiphospholipid syndrome (WAPS). J Thromb Haemost 2005;3:848-853

40. Erkan D, Harrison MJ, Levy R, et al. Aspirin for primary thrombosis prevention in the antiphospholipid syndrome: a randomized, double-blind, placebo-controlled trial in asymptomatic antiphospholipid antibody-positive individuals. Arthritis Rheum 2007;56:2382-2391

41. Farquharson RG, Quenby S, Greaves M. Antiphospholipid syndrome in pregnancy: a randomized controlled trial of treatment. Obstet Gynecol 2002;100:408-413

42. Silver RK, MacGregor SN, Sholl JS, et al. Comparative trial of prednisone plus aspirin versus aspirin alone in the treatment of anticardiolipin antibody-positive obstetric patients. Am J Obstet Gynecol 1993;169:1411-1417

43. Cowchock FS, Reece EA, Balaban D, Branch DW, Plouffe L. Repeated fetal losses associated with antiphospholipid antibodies: a collaborative randomized trial comparing prednisone with low-dose heparin treatment. Am J Obstet Gynecol 1992;166:1318-1327

44. Laskin CA, Bombardier C, Hannah ME, et al. Prednisone and aspirin in women with autoantibodies and unexplained recurrent fetal loss. N Engl J Med 1997;337:148-153

45. Kutteh WH, Rote NS, Silver RK. Antiphospholipid antibodies and reproduction: the antiphospholipid antibody syndrome. Am J Reprod Immunol 1999;41:133152

46. Asherson RA, Espinosa G, Menahem S, et al. Relapsing catastrophic antiphospholipid syndrome: report of three cases. Semin Arthritis Rheum 2008;37:366-372

47. Rubenstein E, Arkfeld DG, Metyas S, et al. Rituximab treatment for resistant antiphospholipid syndrome. J Rheumatol 2006;33:355-357

48. Erre GL, Pardini S, Faedda R, Passiu G. Effect of rituximab on clinical and laboratory features of antiphospholipid syndrome: a case report and a review of literature. Lupus 2008;17:50-55

49. Adams M. Novel considerations in the pathogenesis of the antiphospholipid syndrome: involvement of the tissue factor pathway of blood coagulation. Semin Thromb Hemost 2008;34:251-255 